\title{
Stochastic Modelling of Respiratory System Elastance for Mechanically Ventilated Respiratory Failure Patients
}

\author{
Jay Wing Wai Lee (i), ${ }^{1}$ YeOng Shiong Chiew, ${ }^{1}$ Xin Wang, ${ }^{1}$ \\ Chee Pin Tan, ${ }^{1}$ Mohd Basri Mat Nor, ${ }^{2}$ Nor Salwa Damanhuri, ${ }^{3}$ \\ and J. Geoffrey Chase ${ }^{4}$
}

\begin{abstract}
${ }^{1}$ School of Engineering, Monash University Malaysia, 47500 Subang Jaya, Selangor, Malaysia; ${ }^{2}$ Kulliyah of Medicine, International Islamic University Malaysia, 25200 Kuantan, Pahang, Malaysia; ${ }^{3}$ Faculty of Electrical Engineering, Universiti Teknologi MARA, Cawangan Pulau Pinang, 13500 Bukit Bertajam, Pulau Pinang, Malaysia; and ${ }^{4}$ Center of Bioengineering, University of Canterbury, Christchurch 8041, New Zealand
\end{abstract}

(Received 22 March 2021; accepted 13 August 2021; published online 25 August 2021)

Associate Editor Stefan M. Duma oversaw the review of this article.

\begin{abstract}
While lung protective mechanical ventilation (MV) guidelines have been developed to avoid ventilatorinduced lung injury (VILI), a one-size-fits-all approach cannot benefit every individual patient. Hence, there is significant need for the ability to provide patient-specific MV settings to ensure safety, and optimise patient care. Modelbased approaches enable patient-specific care by identifying time-varying patient-specific parameters, such as respiratory elastance, $E_{\mathrm{rs}}$, to capture inter- and intra-patient variability. However, patient-specific parameters evolve with time, as a function of disease progression and patient condition, making predicting their future values crucial for recommending patient-specific MV settings. This study employs stochastic modelling to predict future $E_{\mathrm{rs}}$ values using retrospective patient data to develop and validate a model indicating future intra-patient variability of $E_{\mathrm{rs}}$. Cross validation results show stochastic modelling can predict future elastance ranges with 92.59 and $68.56 \%$ of predicted values within the 5-95\% and the $25-75 \%$ range, respectively. This range can be used to ensure patients receive adequate minute ventilation should elastance rise and minimise the risk of VILI should elastance fall. The results show the potential for model-based protocols using stochastic model prediction of future $E_{\mathrm{rs}}$ values to provide safe and patient-specific MV. These results warrant further investigation to validate its clinical utility.
\end{abstract}

Keywords-Mechanical ventilation, Stochastic modelling, Respiratory mechanics, Patient-specific ventilation, Elastance, Critical care.

Address correspondence to Jay Wing Wai Lee, and Yeong Shiong Chiew, School of Engineering, Monash University Malaysia, 47500 Subang Jaya, Selangor, Malaysia. Electronic mails: jay.lee1@monash.edu, chiew.yeong.shiong@monash.edu

\section{INTRODUCTION}

Optimal mechanical ventilation (MV) settings are patient-specific and evolve with time as treatment continues. ${ }^{42}$ Landmark trials helped establish guidelines on optimal ranges of mechanical ventilator settings for all patients based on observational data. 7,9,43,44,61 However, a one-size-fits-all approach may benefit many or most patients, but may cause harm to others, failing to cater to individual patient-specific needs. ${ }^{2,11,28,32,46}$

Non-optimal MV settings carry high risks for patients, such as ventilator-induced lung injury (VILI), which exacerbates patient condition, inhibits or delays recovery, and in the worst case, results in organ failure. ${ }^{30,56}$ These risks combined with patient variability require patientspecific MV settings and care. One approach is via personalised, model-based medicine to create adaptive protocols directly managing inter- and intra-patient variability, ${ }^{14,27,42}$ as already emerging in other areas of care. ${ }^{13,57}$ These methods focus on identifying a key patient-specific and clinically relevant "sensitivity" parameter at clinically relevant time intervals, and using it, and its variability, to personalise and guide care. ${ }^{14}$

Patient-specific respiratory system elastance, $E_{\mathrm{rs}}$, is one such sensitivity, ${ }^{14}$ and is a time-varying measure of the elastic properties of the respiratory system, capturing volume response to controlled pressure input or vice versa ${ }^{65} E_{\mathrm{rs}}$ thus provides insight into evolving patient condition. Before directly utilising $E_{\mathrm{rs}}$, one method used to help determine the optimum positive 
end expiratory pressure (PEEP) setting was by using the static pressure-volume (PV) curve. Studies showed that setting PEEP between the upper inflection point (UIP) and lower inflection point (LIP) was associated with improved survival among patients. ${ }^{1,66}$ However, obtaining the static PV curve of each individual patient is cumbersome, requires patient sedation, and is a significant interruption to patient care. ${ }^{42}$ Thus, many works have recommended patient-specific MV settings based on $E_{\mathrm{rs}}$ or a surrogate. ${ }^{10,18,47,49,58,70}$ In fact, the work of Goligher et $a l .^{32}$ most recently showed low tidal volume ventilation strategies resulted in significantly different mortality benefits based on patientspecific $E_{\mathrm{rs}}$. This important outcome indicates the clear potential to optimise MV based on individual, timevarying patient-specific elastance, $E_{\mathrm{rs}}$. Hence, identifying minimum $E_{\mathrm{rs}}$ through model-based methods can potentially provide the means to non-invasively assess patient lung condition without increased risk or clinical workload. ${ }^{10,14,16}$

However, $E_{\mathrm{rs}}$ evolves significantly with time, patient condition, and ventilator settings, such as PEEP. ${ }^{8,17,47,69}$ A better understanding of the variability of $E_{\mathrm{rs}}$ between patients and over time is vital to enable selection of optimal patient-specific MV settings at any current time. Ideally, a deterministic model capturing the entirety of pulmonary mechanics would allow accurate prediction of future lung parameters, if it was accurate and able to be identified, neither of which has been demonstrated due identifiability and validation issues. ${ }^{14}$ Equally, lack of information results in unavoidable simplifications. ${ }^{55}$ This missing data can manifest as unpredictable variability, which cannot be ignored. ${ }^{21}$ To this end, stochastic modelling might hold the solution by grouping indeterminable randomness into a stochastic variable to provide a better picture of system, which has become an increasingly preferred tool to describe biological dynamics. ${ }^{21,68}$ Clinically, one and two variable stochastic models have demonstrated clinical impact and potential in managing variability in glycemic control in the intensive care unit. $^{22,39,41}$

Finally, $E_{\mathrm{rs}}$ has shown to vary significantly with patient condition and ventilator settings. ${ }^{9,17,44}$ Hence, the idea of incorporating a stochastic model to predict future respiratory system mechanics could be explored to potential benefit. In this research, we aim to investigate the feasibility of a stochastic model to capture the variability of mechanically ventilated patients' respiratory system elastance. Specifically, the stochastic model used in this study is generated via modelbased estimated respiratory elastance from airway pressure and flow data of 24 mechanically ventilated patients. This research will provide potential insight to the viability of using a stochastic model to predict fu- ture elastance variation, which can be pre-calculated for computational simplicity to ensure effective, potential clinical implementation. Such an accurate, validated stochastic model could enable risk-based, patient-specific care, as seen in glycemic control. ${ }^{57,64}$

\section{METHODS}

\section{The Single Compartment Linear Lung Model}

The single compartment linear lung model is the most commonly used model to describe mechanically ventilated patient respiratory mechanics ${ }^{65}$ :

$$
P_{\mathrm{aw}}(t)=E_{\mathrm{rs}} V(t)+R_{\mathrm{rs}} \dot{V}(t)+P_{0}
$$

where $P_{\text {aw }}$ represents the airway pressure $\left(\mathrm{cmH}_{2} \mathrm{O}\right), V$ represents the volume of air delivered to the lungs $(L)$, $V$ is the air flow delivered by the ventilator $(L / s)$ and $P_{0}$ is the offset pressure $\left(\mathrm{cmH}_{2} \mathrm{O}\right)$ or positive end-expiratory pressure (PEEP) applied by the ventilator if there is little or no intrinsic PEEP. ${ }^{65}$ Respiratory system elastance $\left(\mathrm{cmH}_{2} \mathrm{O} / \mathrm{L}\right)$ and respiratory system resistance $\left(\mathrm{cmH}_{2} \mathrm{Os} / \mathrm{L}\right)$ are represented by $E_{\mathrm{rs}}$ and $R_{\mathrm{rs}}$, respectively.

Airway pressure, flow and volume can be used to identify $E_{\mathrm{rs}}$ and $R_{\mathrm{rs}}$ using integral-based parameter identification ${ }^{17,26,53}$ in an identifiable problem, ${ }^{25}$ where $E_{\mathrm{rs}}$ is defined as the average elastance of a single breath. ${ }^{16}$

\section{Patient Data and Processing}

This study used the airway pressure-flow data from $24 \mathrm{MV}$ patients prospectively recruited at the International Islamic University Malaysia (IIUM) Medical Centre as part of an observational study under informed consent. ${ }^{15}$ Ventilator data was recorded using the CURE soft system ${ }^{59}$ connected to a Puritan Bennet PB980 ventilator (Covidien, Boulder, CO, USA). Airway pressure $\left(\mathrm{cmH}_{2} \mathrm{O}\right)$ and flow $(\mathrm{L} / \mathrm{min})$ are recorded at a sampling rate of $50 \mathrm{~Hz}$. The collection and use of this data is approved by the IIUM research ethics committee (Ethics Approval Number IREC666).

Recorded data is separated into individual breaths. To mitigate small fluctuations in data, breath filtering criteria are included to ensure an individual breath is a full breath. The criteria are based on the work of Kim et al., ${ }^{35}$ modified to suit the adult cohort in this research, and defined for each breath:

- Start of inspiration is defined as the first overall increase in flow (flow rate $>0.1 \mathrm{~L} / \mathrm{s}$ ) and pressure (Pressure $>\left(\right.$ PEEP $\left.\left.+2 \mathrm{cmH}_{2} \mathrm{O}\right)\right)$. Data is checked 
over the next 8 data points $(0.16$ s) to ensure constant positive flow.

- Start of expiration is defined as the first overall decrease in flow (flow rate $<-0.1 \mathrm{~L} / \mathrm{s}$ ). Data is checked over the next 8 data points to ensure constant negative flow.

- Peak Inspiratory volume reaches a significant value (Peak inspiratory volume $>40 \mathrm{~mL}$ which is $\sim 10 \%$ of typical tidal volume).

- Peak Inspiratory Pressure (PIP) is in the inspiratory phase and is of significant value (PIP > (PEEP $+1 \mathrm{cmH}_{2} \mathrm{O}$ ), where typical PIP is PEEP $\left.+10-14 \mathrm{cmH}_{2} \mathrm{O}\right)$.

- Expiration is detected within $4.125 \mathrm{~s}$ of calculated onset of inspiration as defined above, matching the expected respiratory rate in this cohort.

Lower boundaries for typical values for tidal volume and maximum flow rate are roughly $400 \mathrm{~mL}$ and $60 \mathrm{~L} /$ min respectively. ${ }^{34,67}$ As for PIP, which is essentially the inspiratory pressure setting in addition to PEEP, typical values for inspiratory pressure vary greatly depending on patient condition and clinician preference, with the general aim of keeping plateau pressures under $30 \mathrm{cmH}_{2} \mathrm{O}$. Thus, some guidelines recommend initial inspiratory pressure settings as low as $5-10 \mathrm{cmH}_{2} \mathrm{O} .{ }^{4}$ To help filter noise and fluctuating data, $10 \%$ of these values are used as the threshold to define what constitutes a 'true' breath. Hence, $10 \%$ of $400 \mathrm{~mL}(40 \mathrm{~mL}), 60 \mathrm{~L} / \mathrm{min}(6 \mathrm{~L} / \mathrm{min})$ and $10 \mathrm{cmH}_{2} \mathrm{O}$ $\left(1 \mathrm{cmH}_{2} \mathrm{O}\right)$ are listed as these criteria, which set very low thresholds and thus exclude relatively few breaths while ensuring those breaths captured are not influenced by partial breaths or coughs and asynchrony.

While recording, patients can exhibit asynchronous events or patient effort during breathing. These asynchronous breaths do not accurately reflect the underlying patient-specific pulmonary mechanics as the pressure and flow waveforms are distorted. ${ }^{19,20}$ As this study aims to capture the underlying patient-specific pulmonary mechanics, breaths considered asynchronous are eliminated. As the previously mentioned, the criterion defining a 'true' breathing cycle are generally lenient, and additional criteria are added to further filter noise and asynchronous breathing cycles, which may obscure the process of obtaining the respiratory system elastance. These further criteria indicating an asynchronous breath are also based on the work of Kim et al., ${ }^{35}$ and defined:

- Median model-fit error for a breathing cycle > $15 \%$

- Model-based estimated $E_{\mathrm{rs}} \leq 0$
- Model-based estimated $E_{\mathrm{rs}}$ outside 5th and 95th percentile of collected patient-specific data for that patient

Model-fit for the first criteria is calculated using the median absolute percentage error (APE) between the model's estimated airway inspiration pressure $\left(P_{\text {sim }}\right)$ and measured airway inspiration pressure $\left(P_{\text {mea }}\right)$ shown in Eq. 2. Note, $P_{\text {sim }}$ is calculated using the identified model-based $E_{\mathrm{rs}}$. If $P_{\text {mea }}$ deviates from $P_{\text {sim }}$ too much, its $A P E$ will exceed the threshold, indicating too

$$
\mathrm{APE}=\operatorname{Median}\left(\left|\frac{P_{\mathrm{sim}_{i}}-P_{\text {mean }_{i}}}{P_{\text {sim }_{i}}}\right|\right) \times 100
$$

much noise or asynchrony. These breaths are thus not included in this study.

$E_{\mathrm{rs}}$ is identified and recorded for all remaining breaths, and averaged into mean values over clinically relevant intervals, $E_{\mathrm{rs}, N}$, where $N$ is a selected time interval. For this research, $N$ is arbitrarily chosen as 10 min as a clinically relevant proof-of-concept, and this interval could be varied or changed. The $E_{\mathrm{rs}}$ data is then sorted into data pairs over this interval of $E_{\mathrm{rs}, N}$ and the subsequent interval, $E_{\mathrm{rs}, N+1}$. Thus, $E_{\mathrm{rs}, N}$ defines the mean respiratory elastance of the current 10min interval, and $E_{\mathrm{rs}, N+1}$ defines the mean respiratory elastance of the next subsequent 10-min interval. These data pairs across all time sampled, and across all patients, form the basis of the stochastic model. This process is illustrated in Fig. 1.

\section{Stochastic Model Development}

Stochastic modelling is used to approximate potential outcomes for a process showing a random element. To deal with stochastic processes, probability densities can be created by recording stochastic variables as a function of time. ${ }^{55}$ In this research, a stochastic model of $E_{\mathrm{rs}, N}$ against $E_{\mathrm{rs}, N+1}$ is developed. This stochastic model uses conditional kernel density estimation. ${ }^{5,23} E_{\mathrm{rs}, N}$ is assumed to be a Markov process, in which the probability distribution of future values of $E_{\mathrm{rs}, N}$ can be predicted given the current $E_{\mathrm{rs}, N}$ value only and no past values of $E_{N}$ are required. ${ }^{55}$ This situation is defined:

$$
P\left(E_{\mathrm{rs}, N+1} \mid E_{\mathrm{rs}, 1}, E_{\mathrm{rs}, 2}, E_{\mathrm{rs}, 3} \ldots E_{\mathrm{rs}, N}\right)=P\left(E_{\mathrm{rs}, N+1} \mid E_{\mathrm{rs}, N}\right)
$$

According to Bayes Theorem, the conditional probability has the following property:

$$
P(A \mid B)=\frac{P(A, B)}{P(B)}
$$




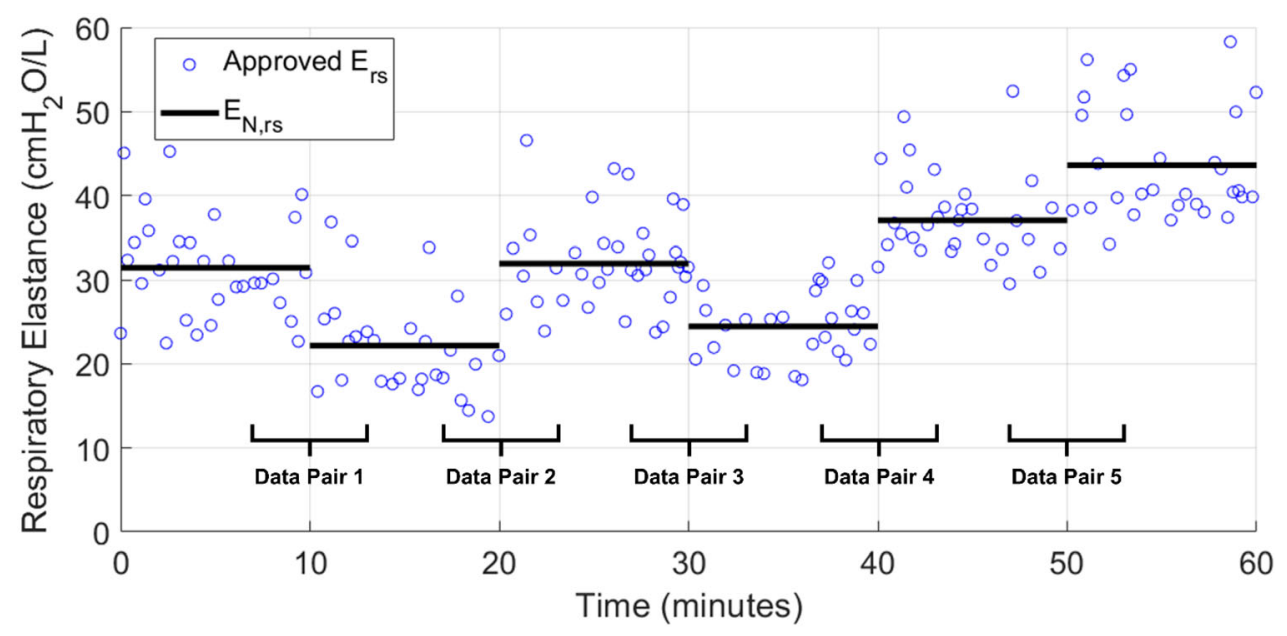

FIGURE 1. Simplified illustration of the obtaining $E_{\mathrm{N}, \mathrm{rs}}$ from the approved breaths and sorting into data pairs.

Hence, $P\left(E_{\mathrm{rs}, N+1} \mid E_{\mathrm{rs}, N}\right)$ can be written:

$$
P\left(E_{\mathrm{rs}, N+1}=x \mid E_{\mathrm{rs}, N}=y\right)=\frac{P\left(E_{\mathrm{rs}, N+1}=x, E_{\mathrm{rs}, N}=y\right)}{P\left(E_{\mathrm{rs}, N}=x\right)}
$$

Equation 5 is the conditional probability function that provides the stochastic information on the potential variation of $E_{\mathrm{rs}}$ which can be obtained using kernel density estimation. ${ }^{33}$ This specific technique of computing conditional probability was adopted from the work of Lin et $a l^{40}$ where this technique was first used to create a stochastic model of insulin sensitivity variation. The right-hand side numerator of Eq. 5 is the kernel density estimated joint probability $P(x, y)$ and can be calculated using the available patient data:

$$
P(x, y)=\frac{1}{n} \sum_{i=1}^{n} \frac{\phi\left(x ; x_{i}, \sigma_{x_{i}}^{2}\right)}{p_{x_{i}}} \frac{\phi\left(y ; y_{i}, \sigma_{y_{i}}^{2}\right)}{p_{y_{i}}}
$$

where

$$
\begin{aligned}
p_{x_{i}} & =\int_{0}^{\infty} \phi\left(x ; x_{i}, \sigma_{x_{i}}^{2}\right) \\
p_{y_{i}} & =\int_{0}^{\infty} \phi\left(y ; y_{i}, \sigma_{y_{i}}^{2}\right)
\end{aligned}
$$

and $x_{i}$ and $y_{\mathrm{i}}$ are the coordinates of each $E_{N}$ data pair which can be seen later in Fig. 5a. Each $\phi\left(x ; x_{i}, \sigma^{2} x_{i}\right)$ and $\phi\left(y ; y_{i}, \sigma^{2} y_{i}\right)$ is a normal probability distribution function centred at a corresponding $x_{i}$ and $y_{i}$. Equations 7 and 8 are used to ensure that the probability distributions are properly normalised, where $p_{x_{i}}$ and $p_{y_{i}}$ represent the area under each normal distribution between zero and infinity and are therefore chosen to be non-negative.
The right-hand side denominator of Eq. 5 can be calculated by obtaining the marginal probability of $P(x)$ from $P(x, y)$ and is done by integrating Eq. 6 .

$$
\begin{aligned}
P(x) & =\int P(x, y) \mathrm{d} y \\
& =\frac{1}{n} \sum_{i=1}^{n} \frac{\phi\left(x ; x_{i}, \sigma_{x_{i}}^{2}\right)}{p_{x_{i}}} \int \frac{\phi\left(y ; y_{i}, \sigma_{y_{i}}^{2}\right)}{p_{y_{i}}} \mathrm{~d} y \\
& =\frac{1}{n} \sum_{i=1}^{n} \frac{\phi\left(x ; x_{i}, \sigma_{x_{i}}^{2}\right)}{p_{x_{i}}} \cdot 1
\end{aligned}
$$

Thus, Eq. 5 can be calculated from Eqs. 6 and 9:

$P\left(E_{\mathrm{rs}, N+1}=x \mid E_{\mathrm{rs}, N}=y\right)=\frac{\sum_{i-1}^{n}\left(\frac{\phi\left(x ; x_{i}, \sigma_{x_{i}}^{2}\right)}{p_{x_{i}}}\right)\left(\frac{\phi\left(y ; y_{i}, \sigma_{y_{i}}^{2}\right)}{p_{y_{i}}}\right)}{\sum_{j=1}^{n} \frac{\phi\left(x ; x_{j}, \sigma_{x_{j}}^{2}\right)}{p_{x_{j}}}}$

Hence Eq. 10 defines the two-dimensional kernel density estimation for the conditional variation of $E_{\mathrm{rs}}$ where $E_{\mathrm{rs}}$ depends on its own prior state. Thus, knowing $E_{\mathrm{rs}}$ at any given interval $N\left(E_{\mathrm{rs}, N}=x\right)$, the probability of $E_{\mathrm{rs}}$ at interval $N+1\left(E_{\mathrm{rs}, N+1}=y\right)$ can be calculated from Eq. 10. A further step-by-step description of how $P(y \mid x)$ is computed can be found in the work of Lin et al. ${ }^{40}$

Once $P\left(E_{\mathrm{rs}, N+1} \mid E_{\mathrm{rs}, N}\right)$ is generated using kernel density estimation, it can be plotted and presented as a stochastic model of elastance variability. Subsequently, the 5th, 25th, 50th, 75th and 95th percentiles lines can be plotted. These percentile lines represent the probability interval for potential $E_{\mathrm{rs}, N+1}$ values. The stochastic model then can be used as a look up table to predict a potential range of $E_{\mathrm{rs}, N+1}$ values given the 
current $E_{\mathrm{rs}, N}$ value, and these ranges can be subsequently used to assess the potential and risk of changes in MV settings and care. Limits of the generated model have been chosen to be $10-100 \mathrm{cmH}_{2} \mathrm{O} / \mathrm{L}$, based on ranges reported in a range of clinical literature ${ }^{7}$ and the data provided from this patient cohort.

\section{Model Validation}

Model development from data requires both selfvalidation for the best case result, and cross-validation to assess the likely performance and ensure the model is robust to the amount of data and patients used. First, the self-validation process is summarised:

1. Build a stochastic model from all data.

2. Generate probability intervals of potential interval elastance $\left(E_{\mathrm{rs}, N+1, \text { sim }}\right)$ from the identified $E_{\mathrm{rs}, N}$ values using the developed stochastic model.

3. Compare predicted $E_{\mathrm{rs}, N+1, \text { sim }}$ probability intervals with actual $E_{\mathrm{rs}, N+1}$ measurements.

The data used to create the model is also the same data as used to test it, providing a best-case estimate.

Second, a 5-fold cross validation is employed, which separates the model creation data and model test data. Data from the entire cohort is randomly divided into 5 groups with approximately equal numbers of data pairs. A stochastic model is then created with 4 of the 5 groups (training sets) with the remaining independent data group is the test set used for validation. This approach creates five validation tests using independent data. Variable outcomes in cross validation would indicate the amount of data used is potentially too low or reliant on specific patients. A schematic of the crossvalidation process is shown in Fig. 2.

For each test, the percentage of predictions within the 25-75th percentile range and those within the 595th percentile range are compared to the ideal values of $50 \%$ and $90 \%$. A good model will have results near the ideal values. Consistency across test sets in crossvalidation will also validate the amount of data used as appropriate.

\section{RESULTS}

Patient Demographics, Breath Data, and Model-Based Lung Mechanics

From a total of 2,086,646 breaths, 2,000,140 $(95.85 \%)$ were identified as true breaths and $1,671,519$ $(80.1 \%)$ remain after filtering asynchronous breaths $(19.9 \%$ asynchrony rate). Individual patient details and demographics are presented in Table 1. Figure 3 shows example breaths failing the initial true breath criteria, while Fig. 4 shows examples of breaths meeting all criteria.

\section{Stochastic Model}

After 10-min averaging, a total of 10,218 values of $E_{\mathrm{rs}, N}$ were obtained, yielding 10,071 pairs of $\left(E_{\mathrm{rs}, N}\right.$, $\left.E_{\mathrm{rs}, N+1}\right)$. Table 1 shows the number of data pairs contributed by each patient. Figure 5a shows the collected mean elastance data sorted into pairs of $E_{\mathrm{rs}, N}$ and $E_{\mathrm{rs}, N+1}$. Figure $5 \mathrm{~b}$ shows the conditional probability density created from the data. The resulting stochastic model for interval elastance is shown in Fig. 5c, and can be now be used as a look-up table to predict future elastance values, as illustrated in Fig. 5d. The coloured lines in Figs. $5 \mathrm{~b}$ and $5 \mathrm{c}$ represent the $N$ th percentile for the $E_{\mathrm{rs}, N+1}$ given $E_{\mathrm{rs}, N}$. For example, in Fig. $5 \mathrm{~d}$, if $E_{\mathrm{rs}, N}=50 \mathrm{cmH}_{2} \mathrm{O} / \mathrm{L}$, the values of $E_{\mathrm{rs}, N+1}$ over the 5th to 95 th probability interval are 44.0-54.5 $\mathrm{cmH}_{2} \mathrm{O} / \mathrm{L}$, while the 25 th to 75 th probability interval covers the range $47.6-51.2 \mathrm{cmH}_{2} \mathrm{O} / \mathrm{L}$. Figure 5e shows

\begin{tabular}{|l|l|l|}
\hline Original data & & Testing set \\
\hline Fold 1 & & \\
\hline Fold 2 & & \\
\hline Fold 3 & Training set & \\
\hline Fold 4 & Fold 5 & \\
\hline
\end{tabular}

FIGURE 2. Illustration of 5-fold cross validation with five groups delineated by shapes and the combinations used in 5-fold cross validation of model creation and independent test sets. 


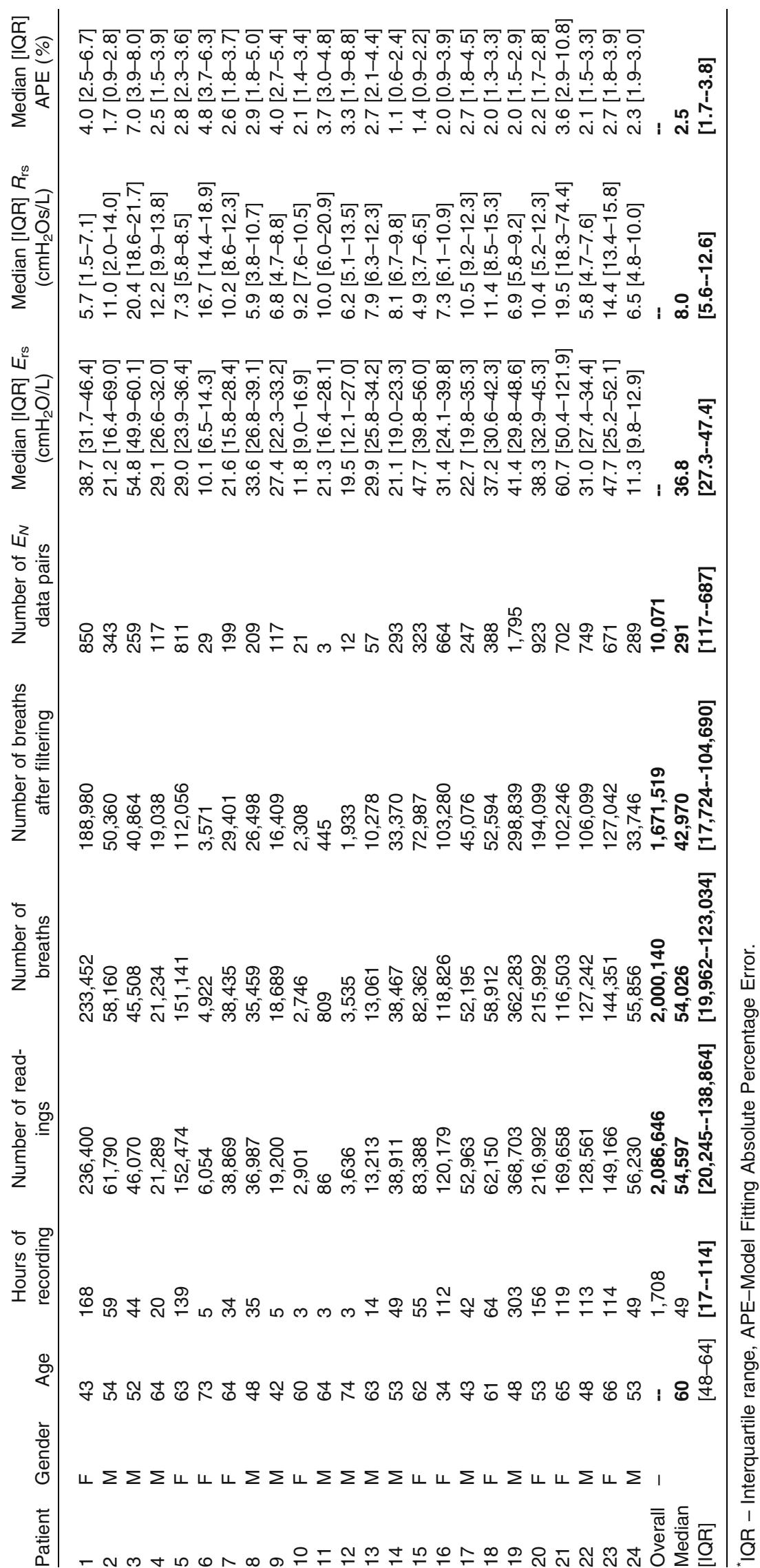



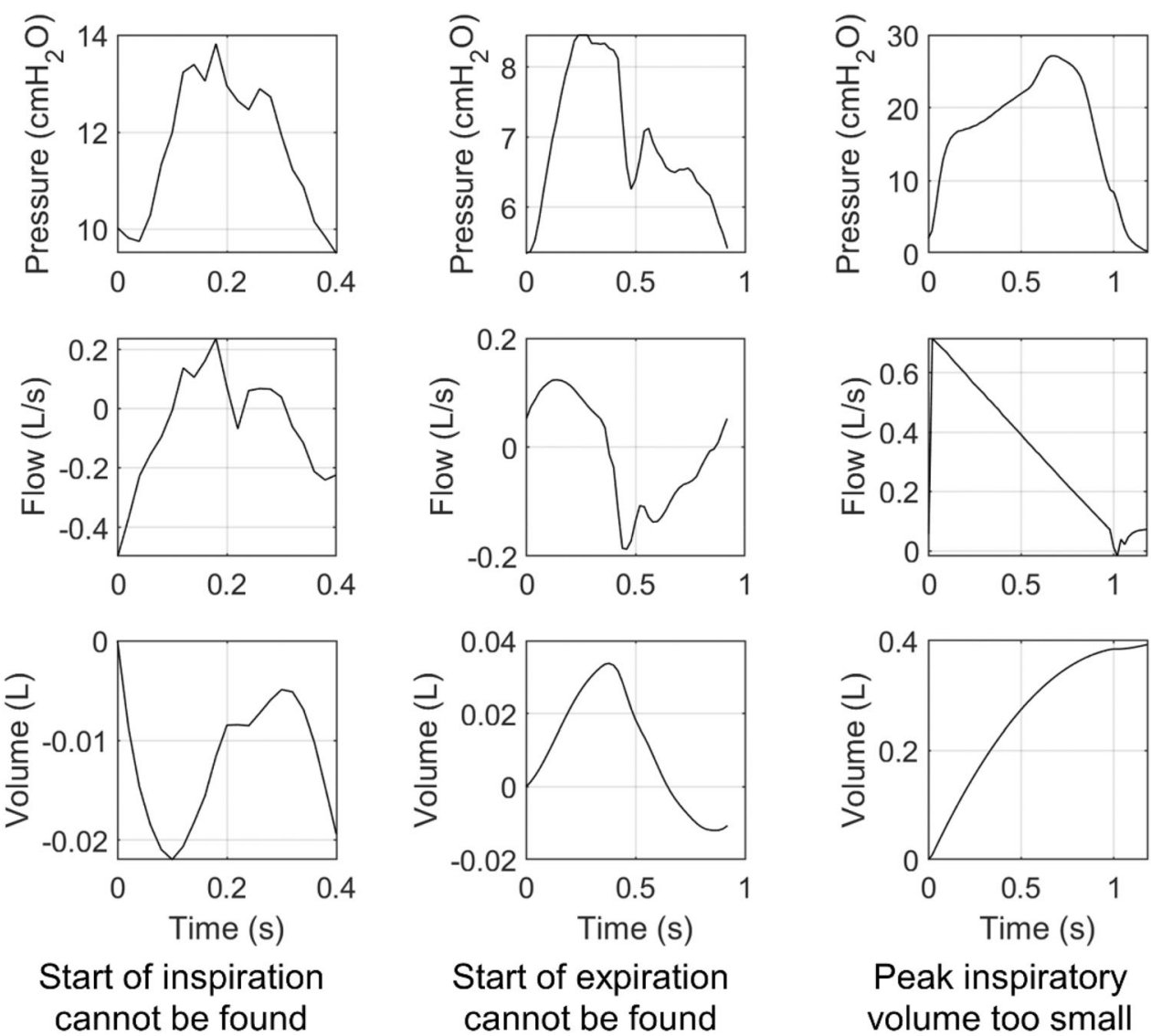

FIGURE 3. Examples of breaths that fail true breath criteria.

a cascade plot of conditional probability functions over a number of possible values of $E_{\mathrm{rs}, N}$.

\section{Self- and Cross-Validation}

Using the stochastic model in Fig. 5c, the data pairs are self-validated against the same data for a best-case result, with results in Fig. 6. Table 2 shows the cross validation results, where the overall results, particularly for the clinically relevant 5-95th percentile range are near $90 \%$. There is modest variability by group indicating the total amount of data might need to be larger considering the 5-95th interval results, even though these results show a very good proof of concept. The strong consistency between self- and crossvalidation results shows the amount of data is more than adequate, as there is no loss in performance.

Figure 7 shows an example of the evolution of $E_{\mathrm{rs}, N}$ over 10-min intervals, with the actual measured $E_{\mathrm{rs}, N}$ shown by the red line and the shaded areas representing the probability intervals of probable $E_{\mathrm{rs}, N+1}$ values generated using the developed stochastic model shown in Fig. 5c. The 5-95\% range is the range between the 5th and 95th percentile prediction of $E_{\mathrm{rs}, N+1} \quad\left(E_{\mathrm{rs}, N+1,5 \mathrm{th}}-E_{\mathrm{rs}, N+1,95 \mathrm{th}}\right)$ and the $25-75 \%$ range is the range between the 25 th and 75 th percentile prediction of $E_{\mathrm{rs}, N+1}\left(E_{\mathrm{rs}, N+1,25 \mathrm{th}}-E_{\mathrm{rs}, N+1,75 \mathrm{th}}\right)$.

\section{DISCUSSION}

Table 1 shows elastance and resistance values for the entire cohort. The elastance values of patients vary substantially with most patient-specific $E_{\mathrm{rs}}$ values lying within ranges reported in literature ${ }^{7,9,43}$ and a few having exceptionally high elastance values. The ranges show the significant inter-patient variability in lung mechanics, and the ranges per-patient show the significant intra-patient variability.

The asynchrony rate calculated using the filtering criteria is $19.9 \%$, which agrees with manual inspection on a portion of this cohort. ${ }^{15}$ Fluctuation, asynchronies, patient effort, and other causes of unreliable data disrupt the ability to identify accurate values of respiratory elastance and resistance. For example, for Patients 6, 11 and 12, almost half the identified breaths are removed due to unidentifiable readings or breaths with $A P E$ values far too high to be considered as unaffected breaths without asynchrony or patient effort. Consequently, Patient 11 is unable to contribute 
any $E_{N}$ data pairs as the little $E_{N}$ data it has are nonsubsequent. In this study, non-subsequent data occurs when either $E_{N}$ or $E_{N+1}$ is missing from the data pair. This result can arise when, within an entire interval from a mechanical ventilated patient, the breaths are noisy, asynchronous, and, as a result, none have passed the filtering criteria. Hence, a data pair cannot be formed, which typically occurs due to significant patient effort occurring for an extended period, or intermittent and limited breath data due to technical difficulties. Furthermore, data collection for Patients 9 to 13 was intermittent due to a technical difficulty with the CURESoft system, and Patient 6 has a lower number of breath data available due to discontinuation of the trial by staff for clinical reasons. However, the overall data set is relatively large for this type of analysis.

The collected $E_{\mathrm{rs}, N}$ pairs are shown in Fig. 5a and are the main foundation of the stochastic model shown in Fig. 5c. The resulting stochastic model in Fig. 5c is very dependent on the data from which it is generated. If given data with lower local data density, the distance between percentile lines (Fig. 5e) would potentially increase to compensate for any greater spread between data, indicating greater variability or lack of data to
FIGURE 5. Stochastic model results. (a) Spread of $E_{\mathrm{rs}, \mathrm{N}}$ data pairs, (b) conditional probability density $P\left(E_{\mathrm{rs}, \mathrm{N}+1} \mid E_{\mathrm{rs}, \mathrm{N}}\right)$, (c) stochastic model percentiles and (d) stochastic model probability intervals. (e) Cascade plot of $E_{\mathrm{rs}, \mathrm{N}}$ probability density functions.

create a more detailed distribution. However, overall data density appears good in Fig. 5 and the resulting stochastic model in Fig. 5c has no discontinuities or inexplicable values.

Figure 5e shows a cascade plot of conditional density functions across the $E_{\mathrm{rs}, N}$ range. From this figure, the conditional probability density functions are largely uni-modal and symmetric except for exceptionally low and high values of $E_{\mathrm{rs}, N+1}$ where data is more scarce. For example, for $E_{\mathrm{rs}, N}=70 \mathrm{cmH}_{2} \mathrm{O} / \mathrm{L}$ and higher, the conditional density functions appear to have more variation in shape, which could indicate the stochastic model of $E_{\mathrm{rs}, N}$ is absorbing an underlying physiology or dynamic not captured by Eq. 1. However, given it only occurs at extremely high values of $E_{\mathrm{rs}, N}$, it is more likely the uneven conditional density function is caused by the data scarcity at these higher values. For this reason, the axis limits of the stochastic model have been limited the $10-100 \mathrm{cmH}_{2} \mathrm{O} / \mathrm{L}$ range.
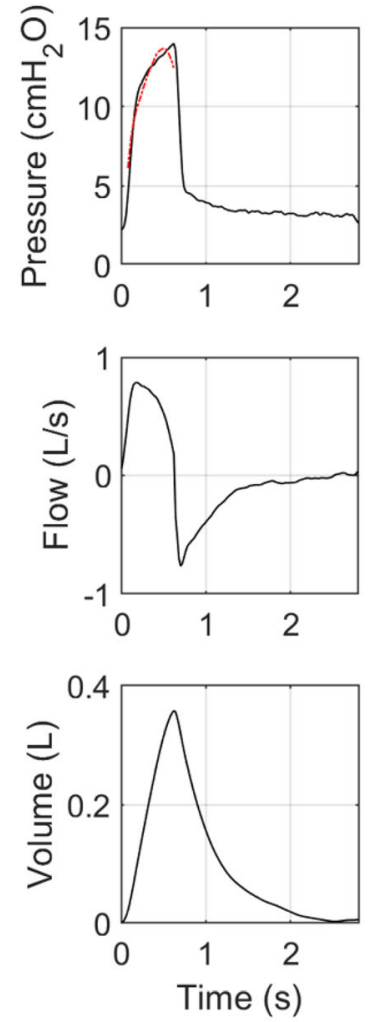

$\mathrm{APE}=2.23 \%$
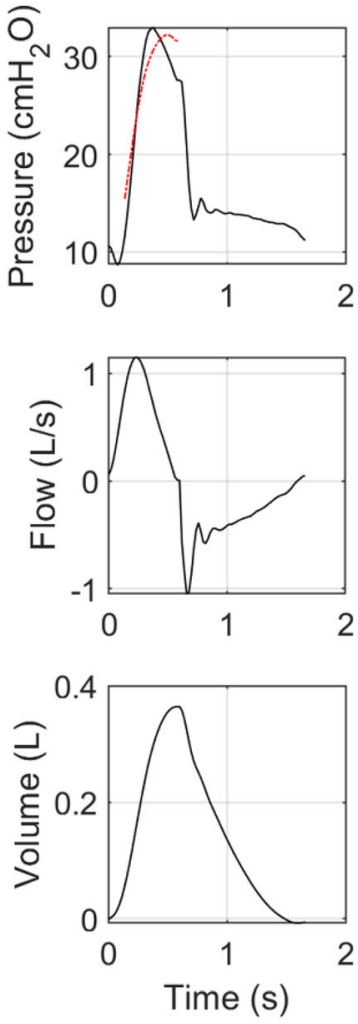

$\mathrm{APE}=8.63 \%$
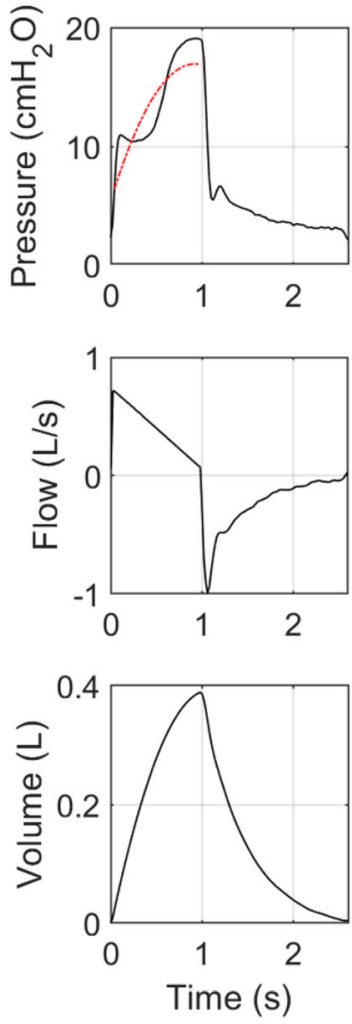

$\mathrm{APE}=12.42 \%$

FIGURE 4. Examples of breaths that meet APE criteria $<15 \%$, with dotted dash line being the model-fitted pressure. 


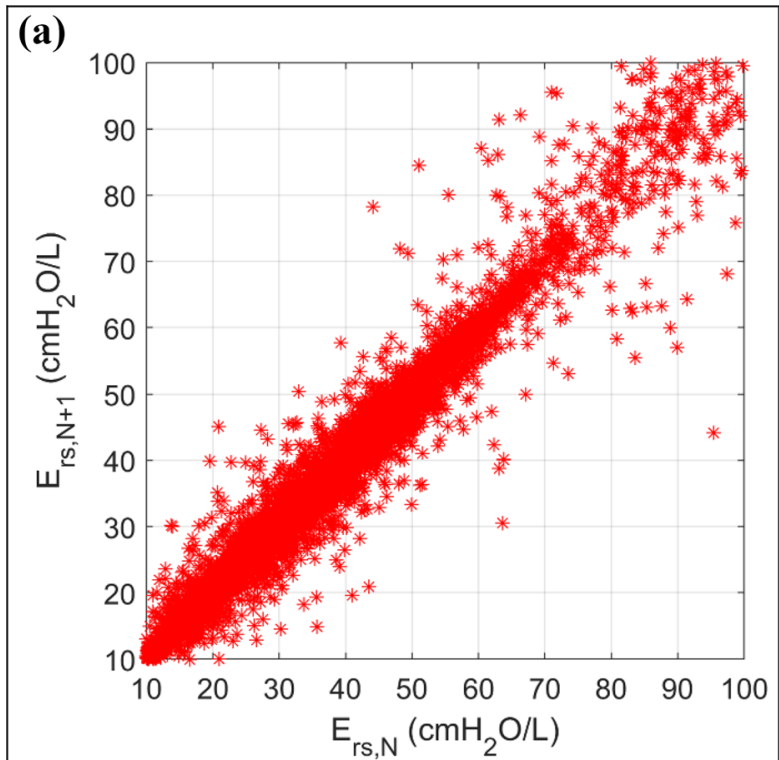

(b)

(c)
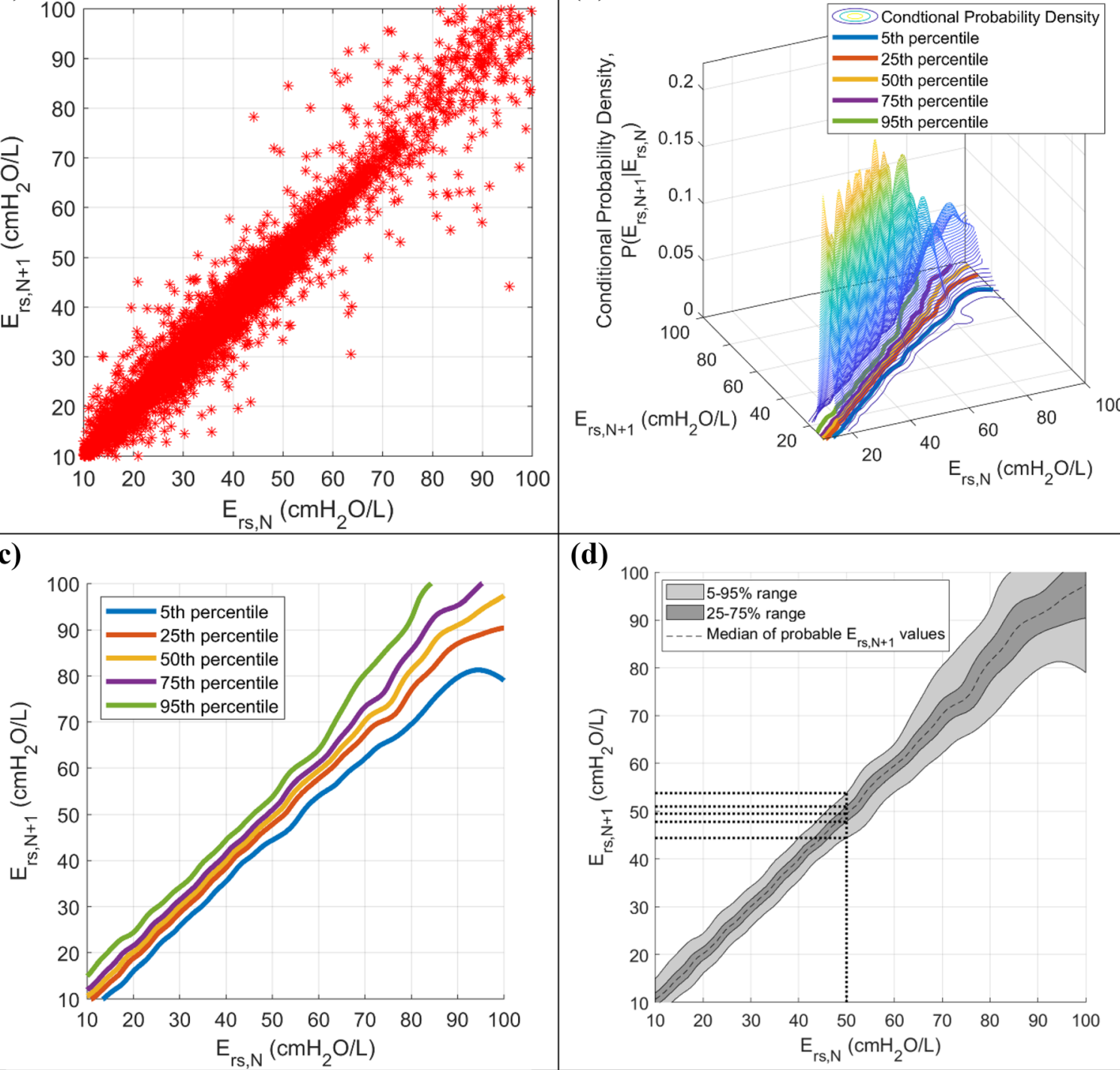

(d)

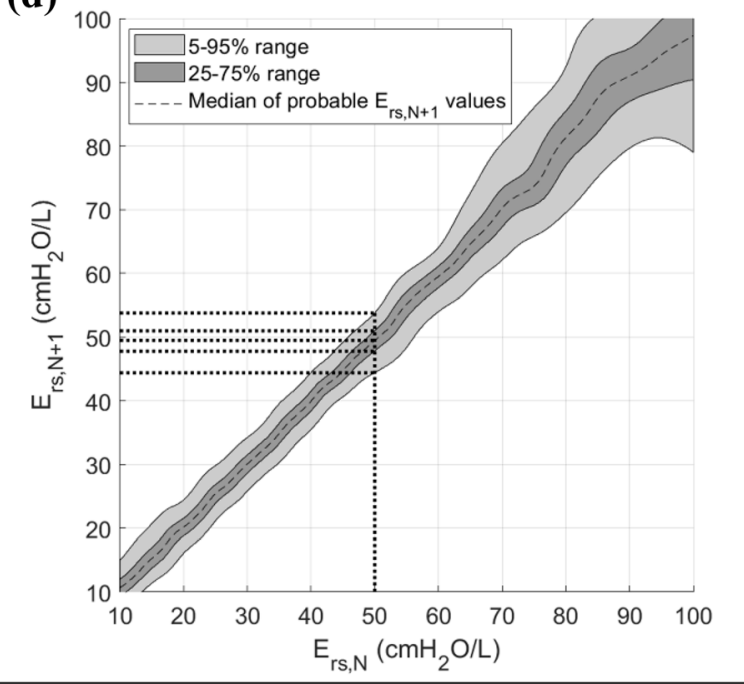

(e)

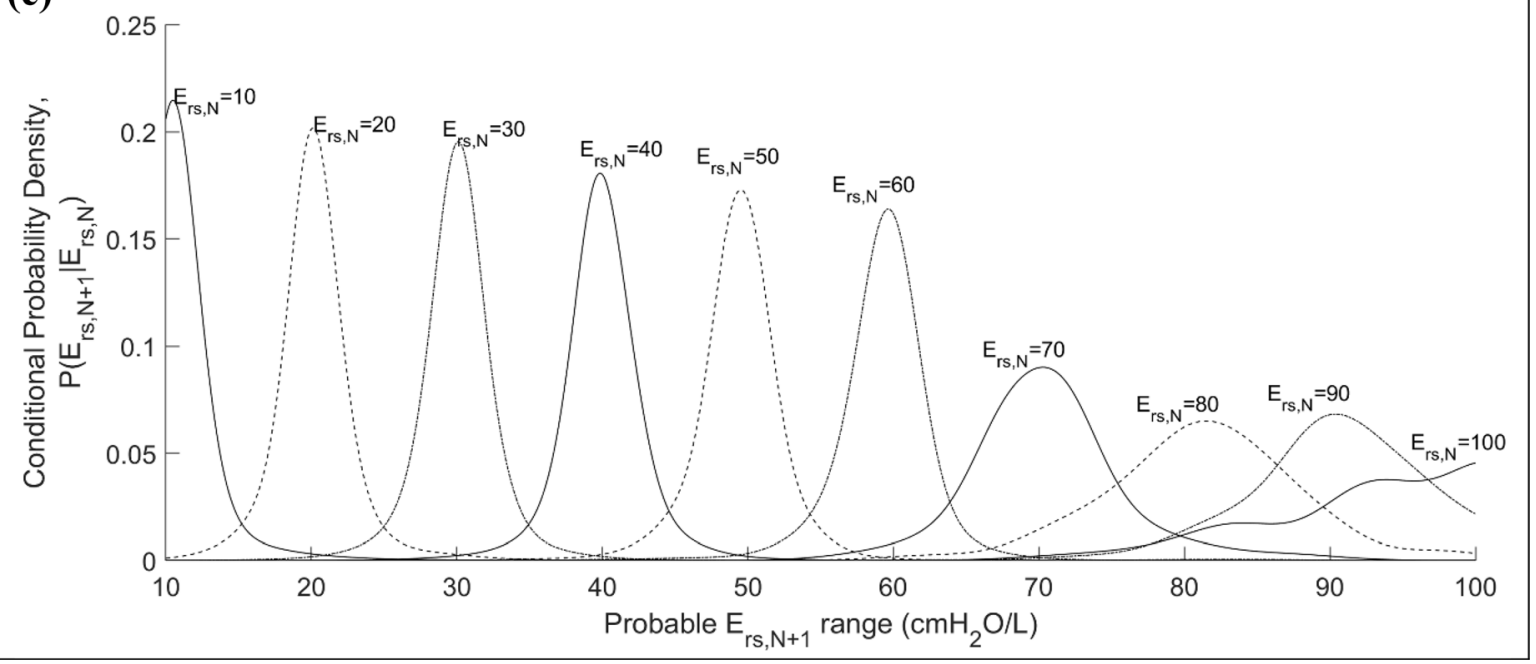




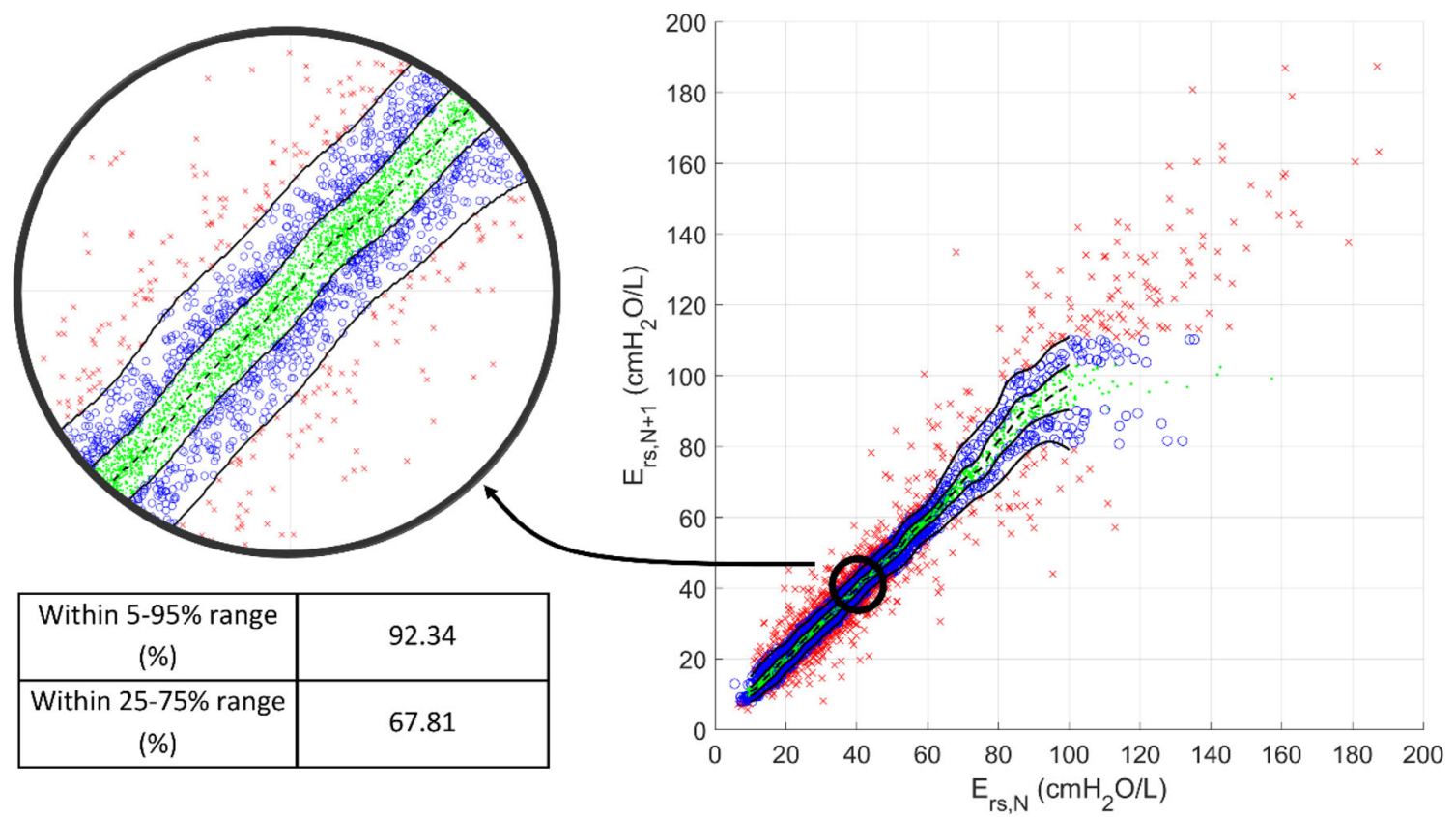

FIGURE 6. Stochastic $E_{\mathrm{rs}, \mathrm{N}}$ model self-validation graphical results, with zoomed-in section solely for clarity. Black solid lines are the percentile lines, dash dotted line is the median percentile, dots are data points within the $25-75 \%$ range, circles are within the $5-95 \%$ range and $x$ 's are outside the prediction range.

TABLE 2. Stochastic $E_{\mathrm{rs}, \mathrm{N}}$ model cross validation results.

\begin{tabular}{|c|c|c|c|}
\hline Group & $\begin{array}{l}\text { Groups used in } \\
\text { creating stochastic } \\
\text { model }\end{array}$ & $\begin{array}{c}\text { Percentage of } \\
\text { actual } E_{\mathrm{rs}, N+1} \text { within } \\
5-95 \% \text { range }(\%)\end{array}$ & $\begin{array}{c}\text { Percentage of } \\
\text { actual } E_{\mathrm{rs}, N+1} \\
\text { within } 25-75 \% \text { range (\%) }\end{array}$ \\
\hline A & {$[-, B, C, D, E]$} & 92.60 & 69.17 \\
\hline B & {$[A,-, C, D, E]$} & 91.71 & 68.49 \\
\hline C & {$[A, B,-, D, E]$} & 92.35 & 67.33 \\
\hline D & {$[A, B, C,-, E]$} & 94.45 & 71.15 \\
\hline $\mathrm{E}$ & {$[A, B, C, D,-]$} & 91.81 & 66.68 \\
\hline \multicolumn{2}{|c|}{ Average \pm standard deviation } & $92.59 \pm 1.12$ & $68.56 \pm 1.74$ \\
\hline
\end{tabular}

${ }^{\mathrm{a}} \mathrm{A}$ hyphen (-) indicates that the group in place was not used as a training set to create the stochastic model.

Further data and larger data sets would enable expansion using the same methodology.

Overall, this model can be used as a look-up table in real-time to predict the next most probable range and distribution of future elastance over the next $N+1$ interval given the current elastance value at interval $N$, as illustrated in Fig. 5d. Knowing the future distribution and range enables MV settings to be optimised using the model in Eq. 1 to minimise risk of extreme values in this range increasing the risk of VILI.

From self-validation results, $92.34 \%$ and $67.81 \%$ of $E_{\mathrm{rs}, N+1}$ fall within the model-predicted 5-95\% and 25 $75 \%$ range, as shown in Fig. 6 . Ideally, 90 and $50 \%$ of the data should lie within these ranges to demonstrate the model perfectly represents the cohort. However, self-validation produces overly optimistic, best case results, as model performance has been evaluated on using the same data to build the model. ${ }^{38}$ Equally, this over estimation is likely due to the assumed normal distributions used in the stochastic model not fully capturing the distributions seen, where a tightening coefficient could be used to improve these results. ${ }^{39}$ However, clinically, such over estimation, which is modest at the clinically more relevant 5-95\% range, would represent a conservative choice as slightly more results lie within this range, thus offering an $\sim 93 \%$ likelihood of elastance in the range.

Table 2 indicates a very similar overall cross-validation performance of $92.59 \%$ and $68.56 \%$ of $E_{\mathrm{rs}, N+1}$ within the $5-95 \%$ and $25-75 \%$ ranges respectively. This performance is encouraging as it is near the ideal values, albeit slightly conservative in over-estimating 


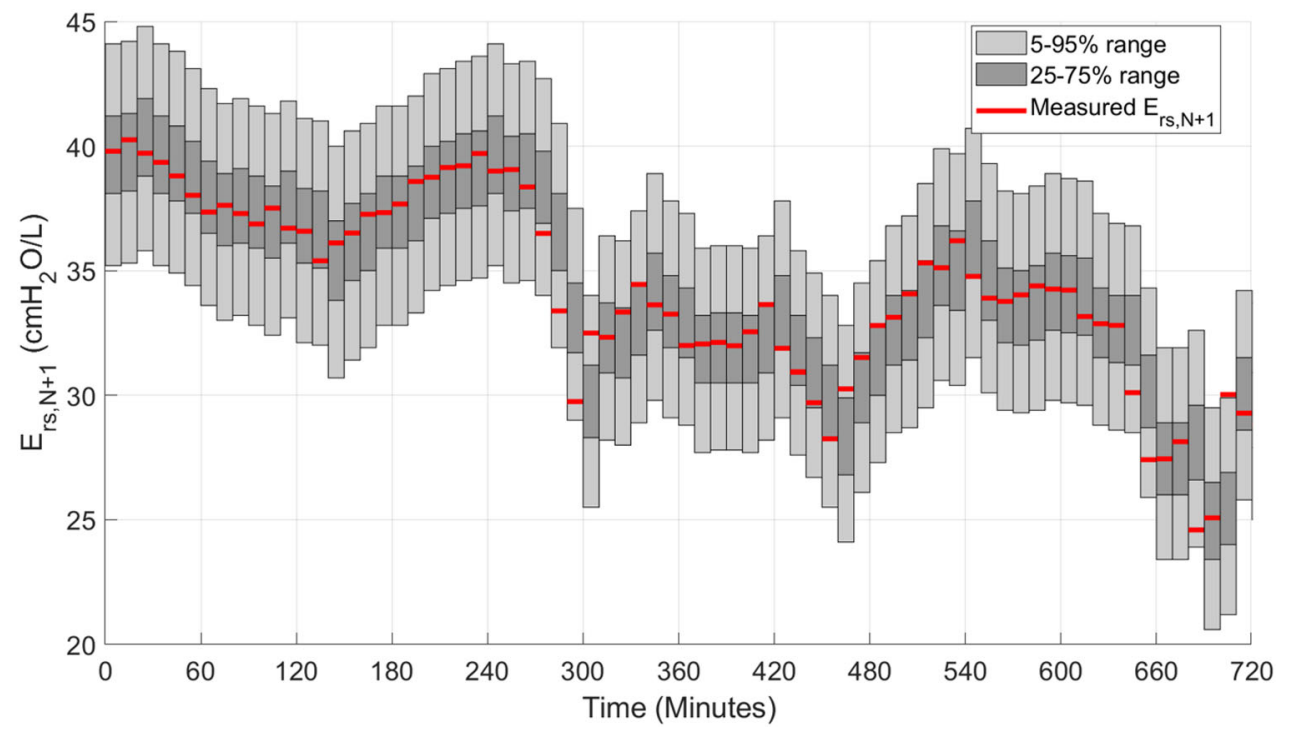

FIGURE 7. Time-step prediction of $E_{\mathrm{rs}, \mathrm{N}+1}$ for first 12 hours of Patient 5, Session 2.

slightly the 5-95th percentile range. The very consistent results for both self- and cross-validation, particularly for the clinically relevant 5-95th percentile range, suggest the model contains sufficient data to account for the range of dynamics observed in this cohort.

As shown in Fig. 7, the potential application of the stochastic model in a clinical setting presents the possibility of better optimising patient-specific ventilator settings. Provided the current patient-specific $E_{\mathrm{rs}, N}$, the stochastic model can predict the likely range of patientspecific $E_{\mathrm{rs}, N+1}$ values over the next $10 \mathrm{~min}$. By utilising the developed stochastic model in a clinical setting, a decision support system can be developed to assist recommending optimal patient-specific MV settings based on the produced patient-specific $E_{\mathrm{rs}, N}$ predictions. The stochastic model can also be utilised together with the single compartment model to predict other parameters, such as pressure and flow which could serve as guides to limit driving pressure and tidal volume settings. However, model-based respiratory mechanics are required as patient specific elastance cannot be directly obtained without an additional realtime computational platform to allow model analysis and identification, breath-to-breath if required. In practice, this potential application would require a computational device to be provided or installed within the ICU or as part of the ventilators themselves (e.g. Refs. ${ }^{48,59}$ ).

More specifically, understanding possible variation in elastance can provide clinicians an approximate forecast of other important parameters, such as monitoring plateau pressure when in volume control ventilation or monitoring tidal volumes when in pressure control ventilation. An illustrative example for volume control ventilation is presented in Fig. 8. The potential process begins with using the stochastic model to predict future $E_{\mathrm{rs}}$. Together with pre-set MV settings, the volume and flow waveform from the ventilator can be used as input to a single compartment model, with airway pressure waveform as the output. By using the 5th and 95th percentiles of predicted $E_{\mathrm{rs}}$, a forecast of plateau pressure can be created. If the forecast value exceeds recommended plateau pressure safety limits of $30 \mathrm{cmH}_{2} \mathrm{O},{ }^{31,42}$ clinicians could pre-emptively adjust other MV settings to avoid potential lung injury. This approach can potentially be used in pressure-controlled ventilation as well to provide a forecast of outcome tidal volume to avoid VILI.

More generally, in pressure controlled MV, the low end of the range would capture risk of volutrauma and the high end the potential risk of under ventilation and atelectasis for any given setting. ${ }^{52}$ These limits can be tested in the same model to pick a best PEEP and other settings to best account for the risk of very high (95th percentile) or low (5th percentile) elastance due to evolution of patient condition over time. Figure 8 illustrates this potential process. This risk-based dosing approach is unique to a limited number of modelbased methods and has been extensively proven clinically in glycemic control studies. ${ }^{12,57,64}$

The prediction interval of the stochastic model was chosen to have prediction limits of 10 to $100 \mathrm{cmH}_{2} \mathrm{O} /$ L. While a majority of elastance values usually fall within this range, ${ }^{3}$ it could be useful to be able to extend the predictive capabilities of the stochastic model beyond these limits. With more patient data, the stochastic model can be extended to much lower and 

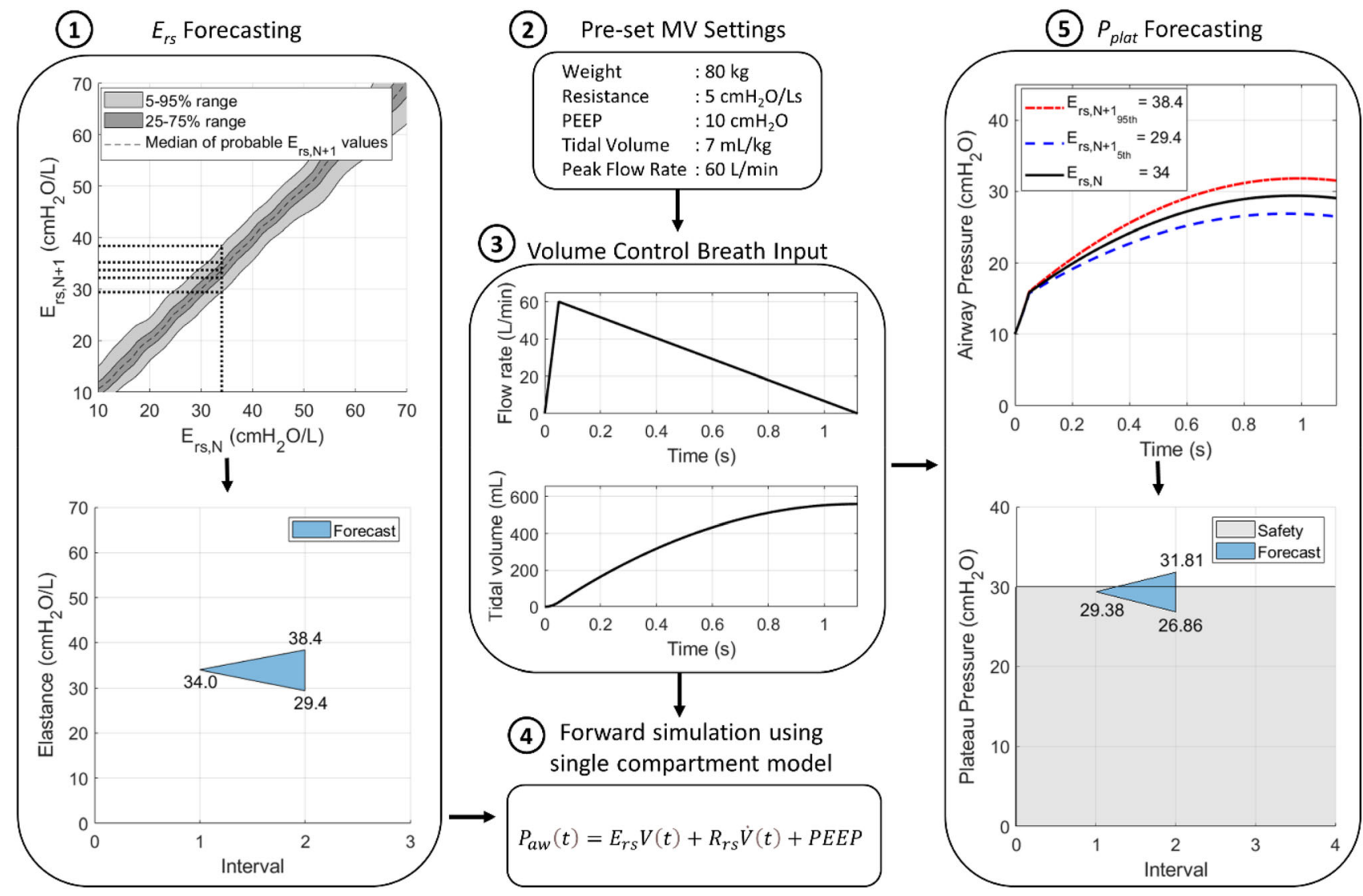

FIGURE 8. Potential application of using $E_{\mathrm{rs}}$ prediction together with pre-set settings to forward simulate possible plateau pressure predictions using the single compartment model. Step 1 uses current patient $E_{\mathrm{rs}}$ to produce a forecast of $E_{\mathrm{rs}}$ at the next interval. In Step 2, pre-set MV settings such can produce the volume and flow breath waveform shown in Step 3. All the information in Step 1, 2 and 3 can then be used as input for a single compartment model in Step 4. The potential output airway pressure waveform is shown in Step 5, and a graph of potential plateau pressures can be forecasted. *Flow, volume, and pressure graphs in this figure only show the inspiratory phase of a single breath. **Plateau pressure safety limit of $30 \mathrm{cmH}_{2} \mathrm{O}$ follows recommendations based on literature. ${ }^{31,42}$.

higher values, as was the case in the glycemic control application. ${ }^{41,63}$ Further studies could include assessing interval to interval variability in sub-cohorts, where similar analyses in glycemic control and MV have found differences between sexes that can impact care. $^{24,36,62}$

Furthermore, the interval size $N$ of $10 \mathrm{~min}$ was arbitrarily chosen as a proof of concept in this work. To link the gap between simulation and practical application to ICU patients, intervention intervals need to be clinically and physiologically relevant to ensure unnecessarily increase of workload, and to capture changes in care in a timely manner. Hence, future work should check the validity of producing stochastic models to predict average future elastance values of longer intervals, such as $30 \mathrm{~min}$ or $1 \mathrm{~h}$, where the 10 min range is a likely lower limit for physiological evolution of lung mechanics in critical illness. However, a larger interval size would require a greater amount of data, which can be collected readily using the software used in this study, noting the number of data pairs in this research was more than adequate given the consistency of results in cross-validation. Such data could arise from clinical trials such as in the work of Kim et al. ${ }^{37}$ Stochastic models with different $N$ values could thus be created to match clinical needs or specific cohorts. With more data, patients can be further broken down into more distinct categories, based on gender, age or probable illnesses. In this study, a broad, diverse range of patients is used to ensure good coverage of patient types and provide enough data to create a valid stochastic model. ${ }^{39,41}$ This model and data level was validated as acceptable in the 5-fold cross validation presented. Overall, it would be valuable to generate unique stochastic models for each subcohort to further increase patient-specificity and further improve personalised care, but it will require a level of data not yet available to the study authors.

While there exist more descriptive lung mechanics models, ${ }^{47,60,69}$ the single compartment linear lung 
model was selected as it forms the basis for all other models, and is readily identifiable using linear and nonlinear basis functions while providing very good predictive accuracy. ${ }^{16,47,65}$ Furthermore, the respiratory elastance and resistance identified using the model has shown to be clinically relevant and similar to those identified from other models. ${ }^{51}$ Finally, more descriptive nonlinear models risk issues, even when identifiable, with model mismatch to dynamics in the observed and measured data, which can lead to inaccurate parameter identification ${ }^{54,71}$ and thus poor prediction and bedside decision support. It is important to note the single compartment linear lung model is also easily identifiable, which is of singular importance so it can be used with available clinical data. While many FEA model studies do a remarkable job of providing thorough descriptions of the physiology of the lung, ${ }^{6,45,50,60}$ many are simply not identifiable, or at least require invasive procedures to assist in identifying specific parameters. This data is often not clinically feasible or available, ${ }^{11}$ and can interrupt patient care and increase clinical workload. Validating the concept of a stochastic model using a relatively simple model will eventually pave the way towards incorporating more descriptive models using the distributions and likelihoods defined in the results of this analysis.

Finally, as noted, the percentages within the 5-95\% and $25-75 \%$ range are higher than the ideal values of 50 and $90 \%$ in both self-validation and cross validation results. This over estimation could indicate over smoothening of the produced stochastic model. Having prediction ranges that are too wide may not help in deducing optimal MV settings. To alleviate this problem, a constant could be introduced to adjust the variance estimators used to produce $P\left(E_{\mathrm{rs}, N+1} \mid E_{\mathrm{rs}, N}\right)$, as done by Le Compte et al. ${ }^{39}$ By adjusting this introduced constant, the produced stochastic model could possess tighter percentile lines which could consequently yield performance results closer towards the ideal 50 and $90 \%$. However, equally, the relatively slight over estimation at the 5-95th percentile interval could be considered a conservative choice and thus useful in clinical implementation. ${ }^{29}$

To surmise, the key potential limitations of this work include the smaller sample size and the relatively simple lung mechanics model used, where these issues trade-off with computational issues of identifiability and the cross validation used. With regards to future work, an increase in available data will not only allow larger interval sizes, but also allow further distinction between patients and patient sub-groups, allowing an even greater level of personalisation via sub-cohort specific stochastic models based on distinctive characteristics, such as gender, age, and diagnoses. Based on the results in this study, it would be interesting to observe the effect on the stochastic model produced if a different lung mechanics model was used, as well to ensure adequacy of the underlying modelling methods in addition to their already demonstrated clinical utility. A more descriptive model could potentially more accurately a stochastic model better reflecting a cohort.

\section{CONCLUSION}

A stochastic model of mechanically ventilated patient-specific respiratory elastance was developed. Cross validation shows promising results with $92.59 \%$ and $68.56 \%$ of actual $E_{\mathrm{rs}, N+1}$ values within the 5-95\% and $25-75 \%$ range respectively. Thus, the model can predict future $E_{\mathrm{rs}, N}$ values well, particularly in the clinically more relevant $5-95$ th percentile range. The overall outcomes justify prospective validation of the clinical utility of this model in helping personalise and more optimally guide mechanical ventilation. Limitations include a smaller sample size, restricting analysis to the full cohort, and relatively simple model used, where these limitations are offset by its identifiability and cross-validation results. Future works point towards increasing the sample size to further categorize patients by age, gender, and diagnosis to create more patient-specific models with greater clinical utility.

\section{ACKNOWLEDGMENTS}

The authors would like to thank the Ministry of Energy, Science, Technology, Environment and Climate Change (MESTECC) research grant (Ref: IF0219I1060), the MedTech Centre of Research Expertise, University of Canterbury, New Zealand and Monash University Malaysia Advance Engineering Platform (AEP) for supporting of this research. The authors would also like to thank members for the research Grant IF0219I1060 for their work in supporting the research.

\section{REFERENCES}

\footnotetext{
${ }^{1}$ Amato, M. B. P., C. S. V. Barbas, D. M. Medeiros, R. B. Magaldi, G. P. Schettino, G. Lorenzi-Filho, R. A. Kairalla, D. Deheinzelin, C. Munoz, R. Oliveira, T. Y. Takagaki, and C. R. R. Carvalho. Effect of a protectiveventilation strategy on mortality in the acute respiratory distress syndrome. N. Engl. J. Med. 338:347-354, 1998.

${ }^{2}$ Amato, M. B. P., M. O. Meade, A. S. Slutsky, L. Brochard, E. L. V. Costa, D. A. Schoenfeld, T. E. Stewart, M. Briel, D. Talmor, A. Mercat, J.-C.M. Richard, C. R. R.
} 
Carvalho, and R. G. Brower. Driving pressure and survival in the acute respiratory distress syndrome. N. Engl. J. Med. 372:747-755, 2015.

${ }^{3}$ Arnal, J.-M., A. Garnero, M. Saoli, and R. L. Chatburn. Parameters for simulation of adult subjects during mechanical ventilation. Respir. Care. 63:158, 2018.

${ }^{4}$ Ashworth, L., Y. Norisue, M. Koster, J. Anderson, J. Takada, and H. Ebisu. Clinical management of pressure control ventilation: an algorithmic method of patient ventilatory management to address "forgotten but important variables." J. Crit. Care. 43:169-182, 2018.

${ }^{5}$ Bashtannyk, D. M., and R. J. Hyndman. Bandwidth selection for kernel conditional density estimation. Comput. Stat. Data Anal. 36:279-298, 2001.

${ }^{6}$ Bates, J. H. A recruitment model of quasi-linear power-law stress adaptation in lung tissue. Ann. Biomed. Eng. 35:1165-1174, 2007.

${ }^{7}$ Briel, M., M. Meade, A. Mercat, R. G. Brower, D. Talmor, S. D. Walter, A. S. Slutsky, E. Pullenayegum, Q. Zhou, D. Cook, L. Brochard, J.-C.M. Richard, F. Lamontagne, N. Bhatnagar, T. E. Stewart, and G. Guyatt. Higher vs lower positive end-expiratory pressure in patients with acute lung injury and acute respiratory distress syndrome: systematic review and meta-analysis. JAMA. 303:865-873, 2010.

${ }^{8}$ Brochard, L., G. S. Martin, L. Blanch, P. Pelosi, F. J. Belda, A. Jubran, L. Gattinoni, J. Mancebo, V. M. Ranieri, and J.-C.M. Richard. Clinical review: respiratory monitoring in the ICU-a consensus of 16. Crit. Care. 16:114, 2012.

${ }^{9}$ Brower, R. G., P. N. Lanken, N. Macintyre, M. A. Matthay, A. Morris, M. Ancukiewicz, D. Schoenfeld, and B. T. Thompson. Higher versus lower positive end-expiratory pressures in patients with the acute respiratory distress syndrome. N. Engl. J. Med. 351:327-336, 2004.

${ }^{10}$ Carvalho, A. R. S., F. C. Jandre, A. V. Pino, F. A. Bozza, J. Salluh, R. Rodrigues, F. O. Ascoli, and A. GiannellaNeto. Positive end-expiratory pressure at minimal respiratory elastance represents the best compromise between mechanical stress and lung aeration in oleic acid induced lung injury. Crit. Care. 11:R86, 2007.

${ }^{11}$ Chase, J., K. Moeller, G. Shaw, C. Schranz, Y. Chiew, and T. Desaive. When the value of gold is zero. BMC Res. Notes. 7:404, 2014

${ }^{12}$ Chase, J. G., B. Benyo, and T. Desaive. Glycemic control in the intensive care unit: a control systems perspective. Annu. Rev. Control. 48:359-368, 2019.

${ }^{13}$ Chase, J. G., T. Desaive, J. Bohe, M. Cnop, C. De Block, J. Gunst, R. Hovorka, P. Kalfon, J. Krinsley, E. Renard, and J.-C. Preiser. Improving glycemic control in critically ill patients: personalized care to mimic the endocrine pancreas. Crit. Care. 22:182-182, 2018.

${ }^{14}$ Chase, J. G., J.-C. Preiser, J. L. Dickson, A. Pironet, Y. S. Chiew, C. G. Pretty, G. M. Shaw, B. Benyo, K. Moeller, S. Safaei, M. Tawhai, P. Hunter, and T. Desaive. Next-generation, personalised, model-based critical care medicine: a state-of-the art review of in silico virtual patient models, methods, and cohorts, and how to validation them. Biomed. Eng. Online. 17:24-24, 2018.

${ }^{15}$ Chiew, Y. S., J. Chase, G. Arunachalam, C. Tan, N. Loo, Y. Chiew, A. Ralib, and M. B. MatNor. Clinical application of respiratory elastance (CARE Trial) for mechanically ventilated respiratory failure patients: a model-based study. IFAC-PapersOnLine. 51:209-214, 2018.
${ }^{16}$ Chiew, Y. S., J. Chase, G. Shaw, A. Sundaresan, and T. Desaive. Model-based PEEP optimisation in mechanical ventilation. Biomed. Eng. Online. 10:111, 2011.

${ }^{17}$ Chiew, Y. S., C. Pretty, P. D. Docherty, B. Lambermont, G. M. Shaw, T. Desaive, and J. G. Chase. Time-varying respiratory system elastance: a physiological model for patients who are spontaneously breathing. PLOS ONE. 10:1, 2015.

${ }^{18}$ Chiew, Y. S., C. G. Pretty, G. M. Shaw, Y. W. Chiew, B. Lambermont, T. Desaive, and J. G. Chase. Feasibility of titrating PEEP to minimum elastance for mechanically ventilated patients. Pilot Feasibility Stud. 1:9, 2015.

${ }^{19}$ Chiew, Y. S., C. P. Tan, J. G. Chase, Y. W. Chiew, T. Desaive, A. M. Ralib, and M. B. MatNor. Assessing mechanical ventilation asynchrony through iterative airway pressure reconstruction. Comput. Methods Progr. Biomed. 157:217-224, 2018.

${ }^{20}$ Damanhuri, N. S., Y. S. Chiew, N. A. Othman, P. D. Docherty, C. G. Pretty, G. M. Shaw, T. Desaive, and J. G. Chase. Assessing respiratory mechanics using pressure reconstruction method in mechanically ventilated spontaneous breathing patient. Comput. Methods Progr. Biomed. 130:175-185, 2016.

${ }^{21}$ Darren, J. W. Stochastic modelling for quantitative description of heterogeneous biological systems. Nat. Rev. Genet. 10:122, 2009.

${ }^{22}$ Davidson, S., C. Pretty, V. Uyttendaele, J. Knopp, T. Desaive, and J. G. Chase. Multi-input stochastic prediction of insulin sensitivity for tight glycaemic control using insulin sensitivity and blood glucose data. Comput. Methods Progr. Biomed. 182:105043-105043, 2019.

${ }^{23}$ De Gooijer, J. G., and D. Zerom. On conditional density estimation. Statistica Neerlandica. 57:159-176, 2003.

${ }^{24}$ Dickson, J. L., J. G. Chase, C. G. Pretty, C. A. Gunn, and J. M. Alsweiler. Hyperglycaemic preterm babies have sex differences in insulin secretion. Neonatology. 108:93-98, 2015.

${ }^{25}$ Docherty, P. D., J. G. Chase, T. F. Lotz, and T. Desaive. A graphical method for practical and informative identifiability analyses of physiological models: a case study of insulin kinetics and sensitivity. Biomed. Eng. Online. 10:3939, 2011.

${ }^{26}$ Docherty, P. D., P. D. Docherty, J. G. Chase, J. G. Chase, T. David, and T. David. Characterisation of the iterative integral parameter identification method. Med. Biol. Eng. Comput. 50:127-134, 2012.

${ }^{27}$ Fan, E., D. Brodie, and A. Slutsky. Acute respiratory distress syndrome advances in diagnosis and treatment. JAMA. 319:698-710, 2018.

${ }^{28}$ Fernandez, A., J. Sturmberg, S. Lukersmith, R. Madden, G. Torkfar, R. Colagiuri, and L. Salvador-Carulla. Evidence-based medicine: is it a bridge too far? Health Res. Policy Syst. 13:1, 2015.

${ }^{29}$ Fisk, L. M., A. J. Le Compte, G. M. Shaw, S. Penning, T. Desaive, and J. G. Chase. STAR development and protocol comparison. IEEE Trans. Biomed. Eng. 59:3357-3364, 2012.

${ }^{30}$ Gajic, O., S. I. Dara, J. L. Mendez, A. O. Adesanya, E. Festic, S. M. Caples, R. Rana, J. L. St. Sauver, J. F. Lymp, B. Afessa, and R. D. Hubmayr. Ventilator-associated lung injury in patients without acute lung injury at the onset of mechanical ventilation. Crit. Care Med. 32:1817-1824, 2004.

${ }^{31}$ Gattinoni, L., P. Caironi, M. Cressoni, D. Chiumello, V. M. Ranieri, M. Quintel, S. Russo, N. Patroniti, R. Cornejo, 
and G. Bugedo. Lung recruitment in patients with the acute respiratory distress syndrome. N. Engl. J. Med. 354:17751786, 2006.

${ }^{32}$ Goligher, E. C., E. L. Costa, C. J. Yarnell, L. J. Brochard, T. E. Stewart, G. Tomlinson, R. G. Brower, A. S. Slutsky, and M. P. Amato. Effect of lowering tidal volume on mortality in ARDS varies with respiratory system elastance. Am. J. Respir. Crit. Care Med. 203:1378, 2021.

${ }^{33}$ Gramacki, A. Nonparametric Kernel Density Estimation and Its Computational Aspects. Cham: Springer, 2018.

${ }^{34}$ Hallett, S., F. Toro, and J. V. Ashurst. Physiology, Tidal Volume. Treasure Island: StatPearls Publishing, 2018.

${ }^{35}$ Kim, K. T., J. Knopp, B. Dixon, and G. Chase. Quantifying neonatal pulmonary mechanics in mechanical ventilation. Biomed. Signal Process. Control. 52:206-217, 2019.

${ }^{36}$ Kim, K. T., J. Knopp, B. Dixon, and J. G. Chase. Mechanically ventilated premature babies have sex differences in specific elastance: a pilot study. Pediatr. Pulmonol. 55:177-184, 2020.

${ }^{37}$ Kim, K. T., S. Morton, S. Howe, Y. S. Chiew, J. L. Knopp, P. Docherty, C. Pretty, T. Desaive, B. Benyo, A. Szlavecz, K. Moeller, G. M. Shaw, and J. G. Chase. Model-based PEEP titration versus standard practice in mechanical ventilation: a randomised controlled trial. Trials. 21:130 130, 2020.

${ }^{38}$ Kuhn, M., and K. Johnson. Applied Predictive Modeling. New York: Springer, 2013.

${ }^{39}$ Le Compte, A. J., D. S. Lee, J. G. Chase, J. Lin, A. Lynn, and G. M. Shaw. Blood glucose prediction using stochastic modeling in neonatal intensive care. IEEE Trans. Biomed. Eng. 57:509-518, 2010.

${ }^{40}$ Lin, J., D. Lee, J. G. Chase, G. M. Shaw, C. E. Hann, T. Lotz, and J. Wong. Stochastic modelling of insulin sensitivity variability in critical care. Biomed. Signal Process. Control. 1:229-242, 2006.

${ }^{41}$ Lin, J., D. Lee, J. G. Chase, G. M. Shaw, A. Le Compte, T. Lotz, J. Wong, T. Lonergan, and C. E. Hann. Stochastic modelling of insulin sensitivity and adaptive glycemic control for critical care. Comput. Methods Progr. Biomed. 89:141-152, 2008.

${ }^{42}$ Major, V., Y. Chiew, G. Shaw, and J. Chase. Biomedical engineer's guide to the clinical aspects of intensive care mechanical ventilation. Biomed. Eng. Online. 17:1-31, 2018.

${ }^{43}$ Meade, M. O., D. J. Cook, G. H. Guyatt, A. S. Slutsky, Y. M. Arabi, D. J. Cooper, A. R. Davies, L. E. Hand, Q. Zhou, L. Thabane, P. Austin, S. Lapinsky, A. Baxter, J. Russell, Y. Skrobik, J. J. Ronco, and T. E. Stewart. Ventilation strategy using low tidal volumes, recruitment maneuvers, and high positive end-expiratory pressure for acute lung injury and acute respiratory distress syndrome: a randomized controlled trial. JAMA. 299:637-645, 2008.

${ }^{44}$ Mercat, A., J.-C.M. Richard, B. Vielle, S. Jaber, D. Osman, J.-L. Diehl, J.-Y. Lefrant, G. Prat, J. Richecoeur, A. Nieszkowska, C. Gervais, J. Baudot, L. Bouadma, and L. Brochard. Positive end-expiratory pressure setting in adults with acute lung injury and acute respiratory distress syndrome: a randomized controlled trial. JAMA. 299:646-655, 2008.

${ }^{45}$ Möller K., J. Kretschmer and C. Schranz. Hierarchical modeling for medical decision support. In: 2011 th International Conference on Biomedical Engineering and Informatics (BMEI) IEEE, 2011, p. 960-964.

${ }^{46}$ Morton, S. E., J. L. Knopp, J. G. Chase, P. Docherty, S. L. Howe, K. Möller, G. M. Shaw, and M. Tawhai. Optimising mechanical ventilation through model-based methods and automation. Annu. Rev. Control. 48:369-382, 2019.

${ }^{47}$ Morton, S. E., J. L. Knopp, J. G. Chase, K. Möller, P. Docherty, G. M. Shaw, and M. Tawhai. Predictive virtual patient modelling of mechanical ventilation: impact of recruitment function. Ann. Biomed. Eng. 47:1626-1641, 2019.

${ }^{48} \mathrm{Ng}$, Q. A., Y. S. Chiew, X. Wang, C. P. Tan, M. B. M. Nor, N. S. Damanhuri, and J. G. Chase. Network data acquisition and monitoring system for intensive care mechanical ventilation treatment. IEEE Access. 9:91859-91873, 2021.

${ }^{49}$ Pintado, M.-C., R. de Pablo, M. Trascasa, J.-M. Milicua, S. Rogero, M. Daguerre, J.-A. Cambronero, I. Arribas, and M. Sánchez-García. Individualized PEEP setting in subjects with ARDS: a randomized controlled pilot study. Respir. Care. 58:1416-1423, 2013.

${ }^{50}$ Polak, A. G., and J. Mroczka. Nonlinear model for mechanical ventilation of human lungs. Comput. Biol. Med. 36:41-58, 2006.

${ }^{51}$ Redmond, D. P., Y. S. Chiew, V. Major, and J. G. Chase. Evaluation of model-based methods in estimating respiratory mechanics in the presence of variable patient effort. Comput. Method Progr. Biomed. 171:67-79, 2019.

${ }^{52}$ Rezoagli, E., and G. Bellani. How I set up positive endexpiratory pressure: evidence- and physiology-based. Crit. Care. 23:412, 2019.

${ }^{53}$ Schranz, C., P. Docherty, Y. Chiew, K. Möller, and J. Chase. Iterative integral parameter identification of a respiratory mechanics model. Biomed. Eng. Online. 11:38, 2012.

${ }^{54}$ Schranz, C., P. D. Docherty, Y. S. Chiew, J. G. Chase, and K. Möller. Structural identifiability and practical applicability of an alveolar recruitment model for ARDS patients. IEEE Trans. Biomed. Eng. 59:3396-3404, 2012.

${ }^{55}$ Schuster, P. Stochasticity in Processes: Fundamentals and Applications to Chemistry and Biology. Cham: Springer, 2016.

${ }^{56}$ Slutsky, A. S., and V. M. Ranieri. Ventilator-induced lung injury. N. Engl. J. Med. 369:2126-2136, 2013.

${ }^{57}$ Stewart, K. W., C. G. Pretty, H. Tomlinson, F. L. Thomas, J. Homlok, S. N. Noémi, A. Illyés, G. M. Shaw, B. Benyó, and J. G. Chase. Safety, efficacy and clinical generalization of the STAR protocol: a retrospective analysis. Ann. Intensive Care. 6:1-10, 2016.

${ }^{58}$ Suter, P. M., H. B. Fairley, and M. D. Isenberg. Effect of tidal volume and positive end-expiratory pressure on compliance during mechanical ventilation. Chest. 73:158$162,1978$.

${ }^{59}$ Szlavecz, A., Y. S. Chiew, D. Redmond, A. Beatson, D. Glassenbury, S. Corbett, V. Major, C. Pretty, G. M. Shaw, B. Benyo, T. Desaive, and J. G. Chase. The Clinical Utilisation of Respiratory Elastance Software (CURE Soft): A bedside software for real-time respiratory mechanics monitoring and mechanical ventilation management. Biomed. Eng. Online. 13:1-14, 2014.

${ }^{60}$ Tawhai, M., A. Clark, and J. Chase. The Lung Physiome and virtual patient models: from morphometry to clinical translation. Morphologie. 103:131-138, 2019.

${ }^{61}$ Network, The Acute Respiratory Distress Syndrome. Ventilation with lower tidal volumes as compared with traditional tidal volumes for acute lung injury and the acute respiratory distress syndrome. N. Engl. J. Med. 342:13011308, 2000.

${ }^{62}$ Uyttendaele, V., J. G. Chase, J. L. Knopp, R. Gottlieb, G. M. Shaw, and T. Desaive. Insulin sensitivity in critically ill 
patients: are women more insulin resistant? Ann. Intensive Care. 11:12-12, 2021.

${ }^{63}$ Uyttendaele, V., J. L. Knopp, S. Davidson, T. Desaive, B. Benyo, G. M. Shaw, and J. G. Chase. 3D kernel-density stochastic model for more personalized glycaemic control: development and in-silico validation. Biomed. Eng. Online. 18:102-102, 2019.

${ }^{64}$ Uyttendaele V., J. L. Knopp, M. Pirotte, P. Morimont, B. Lambermont, G. M. Shaw, T. Desaive and J. G. Chase. STAR-Liège Clinical Trial Interim Results: Safe and Effective Glycemic Control for All. In: 2019 41st Annual International Conference of the IEEE Engineering in Medicine and Biology Society (EMBC)2019, pp. 277-280.

${ }^{65}$ van Drunen, E., Y. Chiew, J. Chase, G. Shaw, B. Lambermont, N. Janssen, N. Damanhuri, and T. Desaive. Expiratory model-based method to monitor ARDS disease state. Biomed. Eng. Online. 12:57-57, 2013.

${ }^{66}$ Villar, J., R. M. Kacmarek, L. Pérez-Méndez, and A. Aguirre-Jaime. A high positive end-expiratory pressure, low tidal volume ventilatory strategy improves outcome in persistent acute respiratory distress syndrome: a randomized, controlled trial. Crit. Care Med. 34:1311-1318, 2006.
${ }^{67}$ Warner M. A. and B. Patel. Mechanical ventilation. Benumof and Hagberg's airway management 981-997. e983, 2013.

${ }^{68}$ Wilkinson, D. J. Stochastic Modelling for Systems Biology. Boca Raton: CRC Press, 2012.

${ }^{69}$ Zhou, C., J. G. Chase, J. Knopp, Q. Sun, M. Tawhai, K. Möller, S. J. Heines, D. C. Bergmans, G. M. Shaw, and T. Desaive. Virtual patients for mechanical ventilation in the intensive care unit. Comput. Methods Progr. Biomed. 199:105912-105912, 2021.

${ }^{70}$ Zhou, C., J. G. Chase, and G. W. Rodgers. Support vector machines for automated modelling of nonlinear structures using health monitoring results. Mech. Syst. Signal Process. 149:107201, 2021.

${ }^{71}$ Zhou, C., J. G. Chase, G. W. Rodgers, and C. Xu. Comparing model-based adaptive LMS filters and a model-free hysteresis loop analysis method for structural health monitoring. Mech. Syst. Signal Process. 84:384-398, 2017.

Publisher's Note Springer Nature remains neutral with regard to jurisdictional claims in published maps and institutional affiliations. 